and the ischium and pubis are both turned backwards, parallel with one another, so as to have almost exactly the same position as in birds. There can be no doubt about this most remarkable point now, as the parts have been found in place in the genus Hypsilophodon. The femur was evidently brought parallel to the long axis of the body, and it has the characteristic ridge between the places of articulation of the tibia and fibula. The tibia has a great crest on its front surface, the fibula is quite small, and the flattened end of the tibia fits on to a pulleyshaped bone exactly like the ankylosed astragalus of a bird. The middle or third toe is the largest, and the outer and inner toes small; the metatarsals, although separate from one another, have their faces so modelled that they must have been quite incapable of movement. Substitute ankylosis for ligamentous union, and a bird's metatarsus is produced; in fact the whole structure of the Dinosaurian hind-limb is exactly that of an embryonic bird.

In the very remarkable genus Compsognathus of the Solenhofen slates, which is nearly allied to the Dinosauria, and included, with them, in the order Ornithoscelida, the head is small, the neck extremely long, and the peculiarities of the hind-limb are entirely bird-like; it also seems that the tibia and astragalus were actually united. The fore-limb, moreover, was very small, and it is certain that Compsognathus must have walked on its hind-legs.

The question, then, naturally arises, did the gigantic Dinosauria, such as Iguandon and Megalosaurus, have the same mode of progression? This seems, at first sight, hard to believe, but there is considerable reason for thinking that it may have been the case, for, in the case mentioned above of the great three-toed footprints of the Connecticut valley and others found in the Wealden formation, no impression of a fore-foot has ever been found; so that, even if we suppose that the impressions of the fore-feet were entirely obliterated, as the animal walked, by those of the hind-feet, the former must, at any rate, have been very small.

When we consider what a very strong piece of evidence this is, we are forced to the conclusion that the evolution of birds from reptiles, by some such process as these facts indicate, is by no means such a wild speculation as it might, from $a$ prior $i$ considerations, have been supposed to be.

(To be continued.)

\section{THE UNEQUAL DISTRIBUTION OF RARE PLANTS IN THE ALPS}

W DE CANDOLLE has recently distributed copies i. 1 . of a paper communicated by him to the Botanical Congress held at Florence in 1874 , in which he explains in a very convincing manner a fact which all botanists have noticed in Switzerland, but the causes of which have not hitherto been properly understood. No one is better acquainted with the plants of the Alps than Mr. Ball, and M: De Candolle prints as a text to his paper a remark made by the well-known author of the Alpine Guide, that it is matter of curious inquiry to ascertain why the vegetation of certain districts of the Alps is more varied than that of others.

Two instances to illustrate this will be sufficient. The mountain chain situated between Italy and the Valais is rich in rare and local plants, while that between the Valais and Canton Bern is very poor; again, after tabulating the species found in Switzerland in single cantons only, while sixty-three are peculiar to the Valais, the Canton Bern has but one.

The explanations which have been given hitherto have

¿ Sur les Causes de l'Inégale Distribution des Plantes rares dans la Châne des Alpes, par Alphonse De Candolle. (Florence, 1875 mainly rested on existing physical causes. Wahlenberg, at the beginning of the century, insisted upon the action of soil and climate. Perrier and Songeon have endeavoured to correlate the distribution of plants with that of different geological formations. Grisebach, more recently, cuts the knot by supposing that the Alps have been a centre of vegetation, and that their present distribution is an ultimate fact.

De Candolle has sought the true reason in the circumstances which accompanied the retirement of the glaciers at the close of the glacial period. "The valleys and groups of mountains which have at present a maximum of rare species and the most varied flora, belong to districts in which the glaciers disappeared soonest. On the other hand, where the duration of snows and glaciers has been most prolonged, the existing flora is poor."

The objection which may be made that a cause so remote can hardly influence the present distribution, is met by pointing out the extreme slowness with which a vegetation establishes itself, and the persistence with which it maintains its status quo when so established. Thus the rare plants for which the botanists of the sixteenth century were accustomed to visit particular localities may still be gathered there. Again, the Rhone valley is intersected by numerous moraines; the lower and more ancient are covered with chestnuts, while the higher are more and more barren and still covered only with pines.

From a variety of causes which De Candolle enumerates, it seems probable that the southern and eastern glaciers of the Alps were of smaller extent than the northern, and would consequently be the soonest to retreat. They also probably furnisbed a refuge amongst their ramifications on smaller mountains which even in the Glacial period would be without snow in the summer, to some of the ancient Alpine and sub-alpine plants which were driven southwards as the glaciers increased.

We have therefore the curious fact that some of the most ancient fragments of the Alpine flora are now only to be found on the sowitiern slopes of the Alps. This is the case with species of Primula, Pedicularis, and Oxytropis, which exist neither in the interior of Switzerland nor in the north of Europe. But it is easy to see that, like the other members of this flora, they were driven south during the Glacial period, returning as the mountains reappeared from underneath their snowy covering; while on the northern side they were in great measure exterminated. De Candolle points out as a fact in further confirmation that the Alpine species of Campanula, peculiar to Mont Cenis and the Simplon and neighbouring valleys, are not related to the Arctic species, but find their nearest allies in Greece, Asia Minor, and the Himalaya.

The Valais was freed from glaciers while the Mont Blanc district and the interior of Switzerland was still in the condition of Greenland. It was gradually stocked by means of species which arrived from France. The first plants to arrive must have been those which are found at the present time on the Jura and the mountains between Geneva and Chamouni. Established at first in the lower part of the valley, they would ascend as the snow diminished. The remarkable plants of the Grande Chartreuse and of Mounts Vergy and Brezon in Savoy, of the higher parts of the Western Jura, and even of the neighbourhood of Bex in Switzerland, probably belong to this period. When the perpetual snow and glaciers had disappeared from these mountains the neighbourhood of the Lake of Geneva, the base of the Jura, and even the commencement of the Valais were more favourably circumstanced. Plants of still more southern origin could then arrive from France. This is probably the date at which the box and many Cistinece and Labiatce, characteristic of dry southern districts, esta. blished themselves at the foot of the Jura. Seeds carried from Italy by winds or birds introduced some of the rare 
species into the Lower Valais, while others of later origin were principally introduced by human agency.

During these changes the Mont Blanc district and the country between the Alps and the Jura were still icebound, and seeds carried by the wind from the south and west would fall on snow or sterile moraines. And when in their turn these districts were released, their opportunity of being stocked by the flora fast disappearing from the lower levels had gone. The asylums which were earliest opened were most richly supplied and have remained so.

M. De Candolle considers that a potent cause of the extermination of this flora has been the destruction of the forests which has rendered the climate south of the Alps hotter and drier in summer, and colder in winter.

The rare plants of the Italian Alps are the remains therefore of an ancient flora like that of St. Helena on its last legs. The climate of Europe tends to become drier, and M. De Candolle thinks it probable that in the course of centuries the centre of Switzerland may in turn become relatively rich in rare species, while the southern slopes of the Alps become poor. In the Lebanon and the Pyrenees this reversal of corditions has actually taken place, and their southern face-once rich probably in species remigrating northwards-is now actually poorer than the northern. The Caucasus and the Himalaya are, however, at present comparable with the Alps.

T. D.

\section{DEEP SEA TELEGRAPH CABLES: HOW THEY ARE TESTED}

THE "testing" of a telegraph cable, whether long or short, proceeds upon the principle that the materials offer to the electrical current a certain resistance : the testing of a cable is the measurement of this resistance. In any cable there are two kinds of these resistance meastrements; one of the resistance which opposes the current in its progress along the conducting wire, the other of that which opposes its lateral dispersion. The conduc. tor-resistance is technically termed the copper-resistance, and is extremely small compared with the other resistance. The lateral resistance to the escape of the current opposed by the insulating substance which surrounds the copper-conductor is technically termed the insulationresistance. Where the resistance to the direct propagation of the electric current through a conducting wire is represented in units, the resistance to lateral dispersion through the insulator will be represented by hundreds, or even thousands of millions, of these units. A third property is that known as the electro-static, or inductive capacity, or simply "charge" 1 of the cable; in other words, that measured quantity of electricity which the given cable will take up in a given time. So much for the necessary explanation of technical terms.

The copper-resistance (I), the insulation-resistance (2), and the "capacity" (3) are the three points to be ascertained in the testing of a cable; and it is useful to inquire why these are the points to be ascertained.

The chief commercial requisite in any cable, and upon which depends its value to its owners, is the speed with which signals can be transmitted. Speed depends directly upon two of the foregoing points (that is upon the copper resistance and "capacity"), and indirectly upon the insulation-resistance. Popular assumption is very much given to the idea that the electrical worth of a cable increases with its insulation-resistance; as usual with popular notions this is only half-truth. That the cost of a cable follows: the ratio may or may not be, but it is certain that above a definite limit the thickness of the insulating coating has no effect upon the practical working condition of the

I "Capacity" and "charge" are not equivalent terms, although they are so considered in this article to prevent confision, by the general reader,

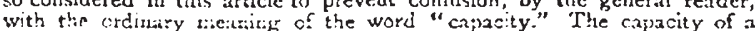
cable remaias constant, while the charge varies with the battery power employed. cable. It may be that minor indirect benefits arise, but with these, under. the present consideration of the practical testing of a cable, we have nothing to do. A certain standard of insulation-resistance attained, there remain the two points, first, of the resistance offered by the copper wire; secondly, of the charge. Now it is collaterally to be understood that, as there can be obtained through a pipe a greater flow of liquid when the pipe offers little resistance to the flow, so through the conductor of a cable can a greater flow be obtained when the conductor has low resistance. With most of the Atlantic cables each nautical mile of the conductor has a resistance equal to that of three to four of the arbitrary units selected by the profession for comparison. There are in use two units of electrical resistance, namely, that determined by a committee of the British Association and the Siemens unit. These units are very nearly of the same value, one Siemens' mercury unit (the resistance offered by a column of pure mercury of one metre length and one square millimetre section at $0^{\circ} \mathrm{C}$.) being equal to $0^{\circ} 953^{6}$ of an $\mathrm{Ohm}$, the technical term for a British Association unit. There is, then, to be considered an electrical length as well as an absolute (or ordinary) length; the proportion that one bears to the other being known, the measures are convertible. Vague as may appear to the reader this idea of electrical resistance, when he knows that of a copper wire of given diameter or weight two lengths offer twice the resistance of one, he is as learned as the most skilled elec. trician who virtually knows no more.

The consideration of the electrical capacity of a cable is more difficult. While the two other points relate to mass, the question of capacity involves that of surface, and of a property of the insulating material of the cable known as its "specific inductive capacity." The material with which long telegraph cables are insulated is gutta-percha. Two different cables may be insulated with this rnaterial to precisely the same dimensions, both as regards the thickness of the insulator and the thickness of the copper wire, but the "charge" taken by these cables may be very different, and the difference will be due to difference in the specific facilities offered by the two gutta-perchas to induction. This difference between various kinds of guttapercha is as inherent as is the difference between resistances to conduction offered by different metallic alloys, and is probably very often due to want of homogeneity of the substance. It is by judicious selection and careful manipulation that the cable manufacturer is enabled to maintain a certain standard for any particular cable in question. Capacity, however, not only varies with the insulating material, but it also varies with the amount of surface of the conductor. It is different with different thicknesses of insulating material, but in this respect, after a certain limit has been passed, the decrease in capacity is very small for very large increase in the thickness of the insulating material.

High charge is incompatible with high speed. That cable will, other conditions the same, have the greatest speed in which the charge, or the fraction of the charge to be altered at each signal, is least. Professional necessity has given rise to a unit of quantity of electricity termed a "farad," of which the "micro-farad" is the millionth part. The capacity of a telegraph-cable generally ranges from three to four-tenths of a micro-farad per nautical mile.

The object of testing a cable is, then, to ascertain whether the insulation reaches the amount specified, and whether the conductor-resistance and the charge are of the required minimum. As these tests are each applied separately to the cable, their consideration will fall under the several heads. It would clearly be impossible within the limits of this paper to describe the many methods which have from time to time been proposed and in use for the testing of telegraph cables. 'The first methods of testing submarine lines are undoubtedly due to Dr. Werner 